shock in the guinea-pig was due to combination of antigen and antibody, not outside but inside the cells, with consequent liberation of histamine.

It is characteristic that in Dale's paper on "The anaphylactic reaction in the plain muscle of the guinea-pig," published in $1913,{ }^{2}$ he did not mention the liberation of histamine. He wrote in 1953, "I suspect that anybody reading this paper, in the light of what is now known and accepted, might detect an excess of caution, even an obstinate reluctance to indulge in the mildest flutter of mental enterprise, in my apparent avoidance of what is now a most obvious link between our own early observations on histamine, and those here recorded on the anaphylactic reaction."

Between so many important advances it is difficult to choose, but many will think that Dale's work on "The action of certain esters and ethers of choline "3 was his most important contribution to physiological theory, calling attention as it did in cautious terms to "the biochemical similarity as shown by their common responsiveness to acetylcholine, between ganglion cells and nerve endings, voluntary motor as well as cranio-sacral involuntary." Here already expressed in 1914 was the possibility that one day acetylcholine might be shown to be the transmitter at all these points.

When Dale became director of the department of biochemistry and pharmacology at the National Institute for Medical Research in 1920, his most important service to medicine in the first five years was his work on biological standardization. Pituitary (posterior lobe) extract as sold in Great Britain varied in potency from 80 to 1 because there was no agreed standard. Neoarsphenamine made by British manufacturers was far less potent than that made in Germany. But, still more important, insulin was discovered by Banting and Best, and here the question of standardization was crucial. Without delay Dale took H. W. Dudley with him to Toronto in order to study both the extraction and preparation of insulin as well as the standardization. The main problem was the definition of a unit of insulin, and at first this was stated in terms of the amount required to cause convulsions in a fasting rabbit of a certain weight. Such a unit showed wide variation, because of the variation in rabbits. Dale's own view was that the method of standardization must be comparative, each preparation being tested in comparison with a standard preparation to determine the difference between them. Meanwhile H.P. Marks, working under Dale's direction, finally arrived at an expression of the hypoglycaemic effect of a given dose of insulin in a group of rabbits in terms of the mean effect in the group. The outcome was a conference in Geneva in 1925 arranged by the Health Organization of the League of Nations. Dale was the chairman. At this conference international standards were agreed upon by representatives of several countries for insulin, pituitary (posterior lobe) extract, neoarsphenamine, sulpharsphenamine, and digitalis. This was a great achievement, which was based on a careful organization of experimental work in different countries beforehand and led to close and friendly relations between all the workers concerned. It meant for insulin that a uniform system for measuring its potency was adopted throughout the world within four years of its discovery, and this was mainly due to Dale's skilful persuasion.

1 Barger, G., and Dale, H. H., f. Physiol. (Lond.), 1910, 41, 19.

- Dale, H. H., f. Pharmacol. exp. Ther., 1913, 4, 167.

- Dale, H. H., f. Pharmacol. exp. Ther., 1914, 6, 147.
Just as Dale in 1910 did not consider the possibility that noradrenaline might be the transmitter of sympathetic impulses because at that time it had not been found in the body, so he did not consider the possibility of acetylcholine as the transmitter of other nerve impulses until 1929, when he together with Dudley identified it as being present in the spleen of the horse. In the following year Dale and Gaddum demonstrated that acetylcholine was liberated on stimulation of the chorda tympani nerve in the cat. They made use of the observation that skeletal muscles become highly sensitive to acetylcholine when the motor nerves to the muscles have degenerated, and showed that stimulation of the chorda tympani led to contracture of the tongue after the hypoglossal nerve had been cut and had degenerated. From their findings they concluded that "the evidence now available makes a very strong case for acetylcholine as the transmitter of parasympathetic effects." Dale with Feldberg in 1934 showed that the sympathetic nerves to the sweat glands in the cat liberated acetylcholine, and in 1936 with Feldberg and Vogt showed that the motor nerves to the skeletal muscles transmitted their impulses in the same way.

This work firmly established humoral transmission as a theory which has, since that time, had a great impact on neurology, on the treatment of myasthenia, and on the practice of anaesthesia. It introduced a new epoch in physiology and pharmacology in which we live today, when so much effort is expended in identifying the transmitter substances for the different pathways in the brain.

In the period up to 1914 Dale seemed a rather reserved person to his colleagues. After the first world war, when he was director of the departments of biochemistry and pharmacology at Hampstead, he was a more forceful figure, deeply concerned to see that the research carried out would be worth while and of a standard to be expected from a National Institute. By the time he reached the age of 60 he had become a commanding personality full of wisdom and with surprising agility of mind. From the beginning his published papers were unique. He was an artist in the preparation of figures to illustrate his results, and few scientists have equalled him in the writing of English prose. His papers are long and written with much care. The arguments are presented in measured sequence, in sonorous sentences, with a remarkable choice of the right words. He was a very great man.

\section{Testing for Allergy}

Measuring the circulating antibody responsible for the wealflare skin reaction to common allergens presents many problems. Human reaginic antibody will not react in conventional precipitation, agglutination, or complement fixation tests. Its qualitative measurement in Prausnitz-Küstner tests, which entail injection of serum, is undesirable in view of the risk of serum hepatitis, and in-vitro tests ${ }^{12}$ have not become established procedures. $\mathrm{K}$. Ishizaka and $\mathrm{T}$. Ishizaka ${ }^{3}$ showed that reaginic activity is mainly confined to IgE immunoglobulin, and S. G. O. Johansson and colleagues ${ }^{4}$ have now developed a radioimmunoassay method for the direct quantitative measurement of human reaginic antibody in serum.

Another approach to the problem of quantitative measurement of human reaginic antibody is the subject of a paper by Dr. E. S. K. Assem and Professor H. O. Schild, F.R.S., 
at page 272 of the B.M.f. this week. They have measured histamine released quantitatively from chopped human lung passively sensitized by reagin-containing serum and reacted with the relevant allergen. Fresh human lung is required, because human reaginic antibody reacts only with human or primate tissues. The quantitative assay of reagin in this method is, as the authors indicate, an indirect one, and its biological standardization still needs to be worked out.

In patients with clinical allergy and positive skin tests to grass pollen, substantial histamine release was detected in all except one. The exceptional patient is important, because positive skin tests and histamine release from her own leucocytes had indicated sensitization of her tissues. Thus measurement of circulating reaginic antibody by this passive sensitization technique does not always reflect the degree of active tissue sensitization. It will be important to know whether reaginic titres measured by this method correlate with the clinical severity of the allergy and with desensitization or other forms of therapy.

This method may be useful for detecting reaginic antibody to antigens which may be undesirable to use in skin tests-for example, some industrial agents. It could also be used to study intrinsic asthma. Not only could a wide range of antigens be tested, but negative results might provide additional evidence in support of other work ${ }^{5}$ that intrinsic asthma does not depend on reagins. It could also be used to establish or exclude the role of reagins in causing asthmatic attacks developing after an interval of some hours following exposure to such antigens as avian proteins ${ }^{6}$ and those causing farmer's lung. ${ }^{78}$

In the second part of their paper Assem and Schild report their results with sera from patients with penicillin allergy. Once again drug hypersensitivity has proved a refractory problem. Only three out of eight sera from patients with established sensitivity gave positive results by the passive sensitization test, usually with only low levels of histamine release. The correlation between these in-vitro studies and the skin tests was also poor. These discouraging results may in part be due to our incomplete knowledge of the molecular structure of the complete antigen and also perhaps because penicillin allergy may also depend on non-reaginic mechanisms; certainly other types of circulating antibody have also been detected in these patients. ${ }^{8}$

There is an urgent need for an in-vitro test for drug allergy, because skin testing is known to be unreliable and sometimes dangerous. It is disappointing that the technique described here does not fill this need. The sequence of tests suggested in this paper to exclude the majority of severe penicillin allergies are both time-consuming and dependent on a ready supply of fresh human or monkey lung; they are therefore at best suitable only when no urgent therapeutic action has to be taken. Unfortunately, as the authors state, complete safety cannot be ensured by any test at present available, so for the time being the best practical solution is to avoid penicillin if there is a suggestive history of hypersensitivity.

1 Shelley, W. B., J. Amer. med. Ass., 1963, 184, 171.

'Ridges, A. P., and Augustin, R., Nature (Lond.), 1964, 202, 667.

' Ishizaka, K., and Ishizaka, T., F. Immunol., 1967, 99, 1187.

- Johansson, S. G. O., Bennich, H., and Wide, L., Immunology, 1968, 14, 265.

"Johansson, S. G. O., Lancet, 1967, $2,951$.

- Pepys, J., Hargreave, F. E., Chan, M., and McCarthy, D. S., Lancet, $1968,2,134$.

' Pepys, J., f. roy. Coll. Phycns Lond., 1967, 2, 42.

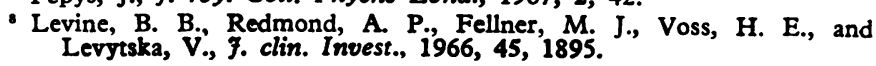

\section{Neurology of Depression}

The successful treatment of much mental depressive illness with drugs implies some kind of physical disorder in the patient's brain. But what this is remains obscure, partly because conventional diagnostic neurology concentrates on reflexes and motor and perceptual tests, ignoring other aspects of central control. Yet there are already some clinical hints of what to look at in the depressed patient. Vegetative symptoms such as anorexia and loss of weight, diminished salivation, constipation, and insomnia are all part of the picture of depressive illness, even if often overshadowed by disturbance of mood or depressive ideation. Vegetative control may be partly hypothalamic, and thence partly exerted through the anterior pituitary and its various hormones, of which corticotrophin (A.C.T.H.) and its stimulation of the secretion and release of cortisol are the best-worked-out mechanisms.

Emotional excitement such as examinations, for instance, can cause a rise in the level of cortisol in the plasma, but more important at present are two other facts. One is that the diurnal variation in the plasma level of cortisol, with a maximum around 8 a.m. every day and a minimum near midnight, is a rhythm dictated by the central nervous system, and changes in its timing may result from lesions in certain areas of the brain. ${ }^{1}$ The second is that the level of plasma cortisol controls the rate at which corticotrophin is released; this is effected through an action of cortisol on the central nervous control of the pituitary and not directly on the gland itself. A sudden rise in plasma cortisol results in a reduced release of corticotrophin and hence a less active adrenal cortex and less secretion of cortisol, and so correction of the level.

Dexamethasone is a synthetic glucocorticoid related to prednisolone. It is not estimated by methods which measure plasma cortisol, yet it acts like cortisol on the nervous system in preventing release of corticotrophin. Consequently, giving dexamethasone lowers the plasma cortisol, and measuring this response tests the functional integrity of the hypothalamo= pituitary-adrenal control of the secretion of cortisol. Dr. B. J. Carroll, Dr. F. I. R. Martin, and Professor Brian Davies in a paper from Melbourne (see page 285) report on the application of this test to severely depressed psychiatric inpatients. They show that many depressives have become unresponsive but recover normal responsiveness when they return to a normal mental state. Thus while they are ill the hypothalamic control is escaping from its normal steroid restraint and corticotrophin continues to be liberated even when the plasma level of steroid rises, until a new higher equilibrium is reached.

This finding agrees with that made by P. W. P. Butler and G. M. Besser ${ }^{2}$ at St. Bartholomew's Hospital. These workers also observed some disturbance of diurnal rhythm during the depression in their three cases, while others ${ }^{3}$ have reported an upset of the diurnal variation which became normal when the patients recovered. There is thus a growing body of evidence that higher nervous control of the pituitary may be altered in depressive illness. The hypothalamic response to intravenous insulin, resulting in secretion of

\footnotetext{
Krieger, D. T., and Krieger, H. P., F. clin Endocrin, 1966, 26, 929.

2 Butler, P. W. P., and Besser, G. M.,'Lancet, 1968, 1, 1234.

Doig, R. J., Mummery, R. V., Wills, M. R., and Elkes, A., Brit. 7 . Psychiat., 1966, 112, 1263.

Greenwood, F. C., Landon, J., and Stamp, T. C. B., F. clin. Invest. $1966,45,429$

s Landon, J., et al., f. clin. Invest., 1966, 45, 437.
} 